\title{
PULMONARY EPITHELIAL SODIUM-CHANNEL DYSFUNCTION AND EXCESS AIRWAY LIQUID IN PSEUDOHYPOALDOSTERONISM
}

\author{
Eitan Kerem, M.D., Tzvy Bistritzer, M.D., Aaron hanukoglu, M.D., Thomas Hofmann, M.D., \\ Zhaooing Zhou, Ph.D., William Bennett, Ph.D., Eithne Maclaughlin, M.D., Pierre Barker, M.D., \\ Martin Nash, M.D., Lynne Quittell, M.D., Richard Boucher, M.D., ANd Michael R. Knowles, M.D.
}

\begin{abstract}
Background Active sodium absorption is the dominant mechanism of ion transport in airway epithelium, but its role in pulmonary physiology and airway host defense is unknown. To address this question, we studied the function of airway epithelial cells and determined the frequency of pulmonary symptoms in patients with systemic pseudohypoaldosteronism, a salt-losing disorder caused by loss-of-function mutations in the genes for the epithelial sodium channel.

Methods In nine patients 1.5 to 22 years of age who had systemic pseudohypoaldosteronism, we tested for mutations in the genes for the epithelial sodium channel, estimated the rate of sodium transport in the airway, determined the volume and ion composition of airway surface liquid, reviewed clinical features, collected laboratory data pertinent to pulmonary function, and, in three adults, measured mucociliary clearance.
\end{abstract}

Results The patients with systemic pseudohypoaldosteronism had loss-of-function mutations in the genes for the epithelial sodium-channel subunits, no sodium absorption from airway surfaces, and a volume of airway surface liquid that was more than twice the normal value. The mean $( \pm S E)$ mucociliary transport rate was higher in the 3 adult patients than in 12 normal subjects $(2.0 \pm 0.7$ vs. $0.5 \pm 0.3$ percent per minute, $\mathrm{P}=0.009$ ). Young patients (those five years of age or less) all had recurrent episodes of chest congestion, coughing, and wheezing, but no airway infections with Staphylococcus aureus or Pseudomonas aeruginosa. Older patients (those more than five years of age) had less frequent respiratory symptoms.

Conclusions Patients with systemic pseudohypoaldosteronism fail to absorb liquid from airway surfaces; the result is an increased volume of liquid in the airways. These results demonstrate that sodium transport has a role in regulating the volume of liquid on airway surfaces. (N Engl J Med 1999;341: 156-62.)

(C)1999, Massachusetts Medical Society.

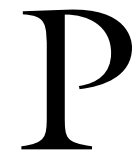
SEUDOHYPOALDOSTERONISM is a rare syndrome characterized by defective sodium transport in the distal nephron and renal salt wasting despite high serum aldosterone concentrations. Two clinically distinct forms of pseudohypoaldosteronism have been described.1 The systemic form is characterized by salt loss from multiple organs, including the kidneys, colon, salivary glands, and sweat ducts. It is inherited as an autosomal recessive trait and is caused by loss-of-function mutations in the genes for an epithelial sodium channel in those tissues. ${ }^{2,3}$ The renal form is characterized by salt loss from the kidneys. It is inherited as an autosomal dominant trait and is caused by mutations in the mineralocorticoid-receptor gene. ${ }^{4}$ Both forms of pseudohypoaldosteronism present in the first week of life with dehydration, hyponatremia, and hyperkalemia. Children with systemic, but not renal, pseudohypoaldosteronism have frequent lower respiratory tract illnesses of unknown cause..$^{5,6}$

It is difficult to predict the phenotype and pathophysiology of lung disease in patients in whom airway epithelial sodium transport may be absent. Active sodium absorption is the dominant pathway of ion transport in airway epithelium, but the relations among sodium transport, the volume and composition of airway surface liquid, and the efficiency of mucociliary clearance have not been clearly defined.7-12 If sodium-channel mutations associated with systemic pseudohypoaldosteronism cause a loss of airway sodium transport, the study of patients with these mutations would provide an opportunity to determine the role of sodium transport in the physiology of airway surface liquid and, possibly, defense against lung disease. Therefore, we studied airway epithelial sodium transport and the volume and composition of airway surface liquid in patients with pseudohypoaldosteronism and characterized their pulmonary syndrome.

From the Pediatric Respiratory Medicine and Cystic Fibrosis Center, Shaare Zedek Medical Center, Hebrew University Medical School, Jerusalem, Israel (E.K.); the Department of Pediatrics, Assaf Harofeh Medical Center, Zerifin, Israel (T.B.); the Department of Pediatrics, Wolfson Medical Center, Holon, Tel Aviv University Sackler School of Medicine, Tel Aviv, Israel (A.H.); Justus Liebig Universität Kinderklinik, Pädiatrische Pneumonologie, Giessen, Germany (T.H.); the Cystic Fibrosis-Pulmonary Research and Treatment Center (Z.Z., P.B., R.B., M.R.K.) and the Center for Environmental Medicine (W.B.), University of North Carolina at Chapel Hill; the Division of Pediatric Pulmonology, Childrens Hospital Los Angeles and the University of Southern California, Los Angeles (E.M.); and the Pediatric Nephrology Division (M.N.) and Pediatric Pulmonary Division (L.Q.), Columbia-Presbyterian Medical Center, New York. Address reprint requests to Dr. Knowles at the Cystic Fibrosis-Pulmonary Research and Treatment Center, 7011 Thurston-Bowles Bldg., CB 7248, University of North Carolina at Chapel Hill, Chapel Hill, NC 27599-7248, or at knowles@med.unc.edu.

Other authors were Vera Homolya, M.S. (University of North Carolina, Chapel Hill), and Bruce Keenan, M.D. (Department of Pediatrics, University of Texas, Galveston). 
Table 1. Demographic Characteristics, Sweat and Salivary Electrolyte Concentrations, and Genotypes of Patients with Systemic Pseudohypoaldosteronism.*

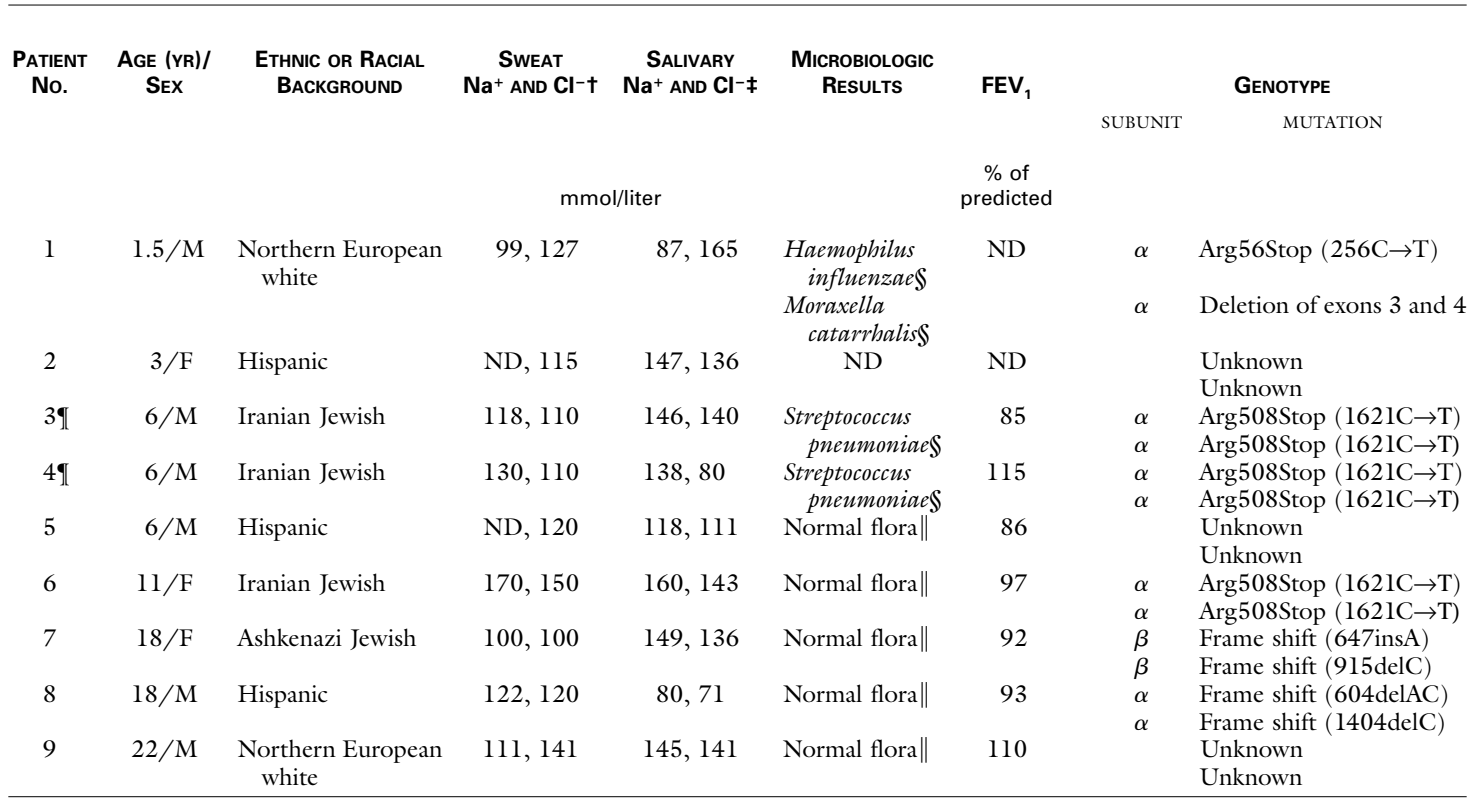

${ }^{*} \mathrm{FEV}_{1}$ denotes forced expiratory volume in one second, ND not determined, $\mathrm{C}$ cytosine, $\mathrm{T}$ thymidine, and $\mathrm{A}$ adenine.

$\dagger$ Normal sweat sodium and chloride concentrations were $<70 \mathrm{mmol}$ per liter and $<60 \mathrm{mmol}$ per liter, respectively.

$\ddagger$ Normal salivary sodium and chloride concentrations are $<60 \mathrm{mmol}$ per liter.

\$Microbiologic results are from culture of bronchoalveolar-lavage specimens.

IPatients 3 and 4 are dizygotic twin brothers.

\|Microbiologic results are from culture of sputum.

\section{METHODS}

\section{Subjects}

We studied nine patients from eight families with systemic pseudohypoaldosteronism (Table 1) and four patients from three families with renal pseudohypoaldosteronism (three boys and one girl 6 to 10 years of age). The diagnosis of pseudohypoaldosteronism was based on severe renal salt wasting in early infancy in association with hyponatremia, hyperkalemia, metabolic acidosis, hyperreninemia (plasma renin activity of more than $10 \mathrm{ng}$ per milliliter per hour [2.8 ng per liter per second]), and hyperaldosteronism (serum aldosterone concentrations greater than $100 \mathrm{ng}$ per deciliter [2700 pmol per liter]), but who otherwise had normal adrenal function. The patients with systemic pseudohypoaldosteronism, but not those with renal pseudohypoaldosteronism, had high sodium and chloride concentrations in the saliva and sweat (Table 1). Gastroesophageal reflux had been diagnosed in six of the children 1.5 to 6 years of age with pseudohypoaldosteronism ${ }^{13}$; two had undergone Nissen fundoplication, with no change in respiratory symptoms. Two of the patients (Patients 6 and 9) have previously been described. ${ }^{2,14}$ The study was approved by the human-rights committees at all participating centers, and informed consent was obtained from all patients or their parents.

\section{Clinical Evaluation}

In all the patients we evaluated respiratory symptoms and performed a physical examination. In most patients, we performed chest and sinus radiography and microbiologic examination of sputum or bronchial-lavage fluid; determined atopic status by skin-prick testing ${ }^{15}$; determined the clinical or spirometric response to an inhaled $\beta$-agonist drug or a glucocorticoid; and performed spirometry. In some patients, we measured lung volumes by body plethysmography or functional residual capacity by the nitrogen-washout technique, the diffusing capacity of the lung by the carbon monoxide technique, and bronchial reactivity by methacholine challenge. ${ }^{16-19}$

\section{Detection of Mutations}

Genomic DNA isolated from peripheral leukocytes or messenger RNA isolated from nasal epithelium was tested for mutations in the genes encoding the $\alpha, \beta$, and $\gamma$ subunits of the epithelial sodium channel by single-strand conformation polymorphism analysis with the use of products amplified by the polymerase chain reaction ${ }^{2,20}$ and by direct-sequencing analysis.

\section{Sodium Transport in the Airway Epithelium}

Rates of sodium transport in nasal and bronchial epithelium were estimated by measuring the basal transepithelial voltage and determining the reduction in voltage during luminal perfusion of amiloride $\left(10^{-4} \mathrm{M}\right)$ or sodium-free Ringer's solution. ${ }^{21,22}$

\section{Volume and Composition of Airway Surface Liquid}

Nasal and bronchial surface liquids were collected by the filterpaper technique. ${ }^{23}$ In two patients with systemic pseudohypoaldosteronism, approximately $3 \mathrm{ml}$ of clear liquid was aspirated from bronchial surfaces with a transbronchoscopic catheter. Ion composition, volume, and osmolarity $\left[2\left(\left[\mathrm{Na}^{+}\right]+\left[\mathrm{K}^{+}\right]\right)\right]$were estimated as described previously. ${ }^{23}$ 


\section{Bronchoscopy}

Three patients underwent diagnostic bronchoscopy, and research studies were performed during the procedure. Two patients (both 6 years of age) were sedated with parenteral midazolam, fentanyl, and atropine, and one patient (18 months of age) was sedated with parenteral propofol. Lidocaine ( 2 percent) was applied only to the pharynx and vocal cords. After the collection of surface liquid, a $3.5-\mathrm{mm}$ bronchoscope (model 20PD or 3C20, Olympus, Lake Success, N.Y.) was wedged in the right lower lobe for bronchoalveolar lavage (three aliquots of $1 \mathrm{ml}$ of normal saline per kilogram of body weight). The lavage fluid was cultured for quantitative determination of bacteria ${ }^{24}$ and was examined for cells and protein. ${ }^{23}$

\section{Mucociliary Clearance}

In three adults with systemic pseudohypoaldosteronism, clearance rates of technetium- $99 \mathrm{~m}$-labeled iron oxide particles (median diameter, $4.5 \mu \mathrm{m}$ ) from the lungs were determined by gammacamera analysis. ${ }^{25}$ The initial deposition patterns were determined, and activity in the right lung was monitored for two hours. Clearance rates (percentage cleared per minute) were calculated from a best-fit regression of retained activity against time and compared with values in normal adults. ${ }^{25}$

\section{Statistical Analysis}

Values are expressed as means \pm SE. Bioelectric and electrolyte values for each nostril were averaged to give a value for each subject. The differences between study groups were compared by nonpaired t-tests. The difference between the mucociliary clearance rates in the normal subjects and in the patients with systemic pseudohypoaldosteronism was evaluated by the Kruskal-Wallis test. ${ }^{26}$

\section{RESULTS}

\section{Course of Respiratory Disease}

All patients with systemic pseudohypoaldosteronism had salt wasting and electrolyte disturbances 24 to 72 hours after birth, but none had respiratory symptoms. Within weeks or months after birth, all patients had respiratory illnesses (three to six per year) characterized by chest congestion, cough, and tachypnea and often associated with fever, wheezing and crackles, and mild leukocytosis. Blood cultures were negative, and bacterial causes were not identified. In patients more than five years of age, respiratory illnesses were less severe and less frequent. Skin tests were negative for common allergens. No patient had digital clubbing, chronic sinusitis, clinical or radiographic evidence of bronchiectasis, or airway infection with Staphylococcus aureus or Pseudomonas aeruginosa.

\section{Genotypes in Patients with Systemic Pseudohypoaldosteronism}

Three patients, each born to consanguineous parents, were homozygous for a stop mutation (Arg508Stop) resulting from a cytosine-to-thymidine mutation at nucleotide 1621 of the gene for the $\alpha$ subunit of the sodium channel (Table 1). One patient had two frame-shift mutations in the gene for the $\alpha$ subunit (deletion of adenine and cytosine at nucleotide 604 and deletion of cytosine at nucleotide 1404), one patient had two frame-shift muta-

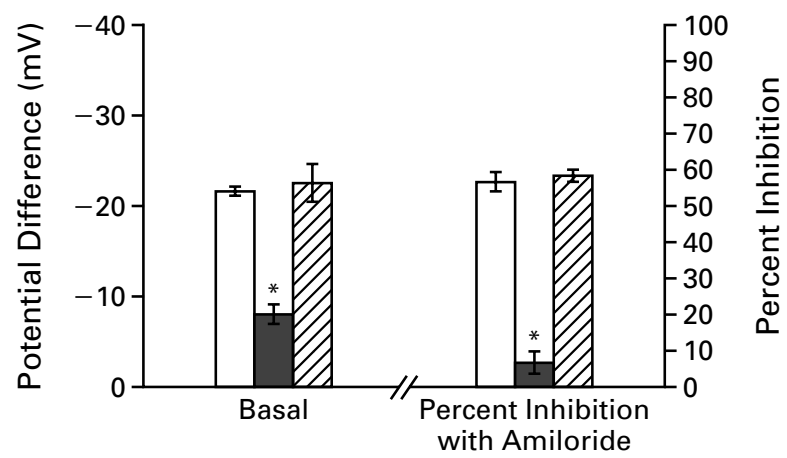

Figure 1. Mean ( \pm SE) Bioelectric Indexes of Nasal Epithelial Sodium Transport in 33 Normal Subjects (Open Bars), 9 Patients with Systemic Pseudohypoaldosteronism (Solid Bars), and $3 \mathrm{~Pa}$ tients with Renal Pseudohypoaldosteronism (Hatched Bars).

The data from the normal subjects (age range, 1.5 to 22 years) were reported previously. ${ }^{21}$ Asterisks indicate $\mathrm{P}<0.001$ for the comparison with normal subjects and with patients with renal pseudohypoaldosteronism. Values shown are basal values (before perfusion of the lumen with amiloride) and percent inhibition (after perfusion).

tions in the gene for the $\beta$ subunit (insertion of adenine at nucleotide 647 and deletion of cytosine at nucleotide 915), and one patient had one stop mutation (Arg56Stop, resulting from a cytosine-to-thymidine mutation at nucleotide 256) and one in-frame deletion (deletion of exons 3 and 4 ) in the gene for the $\alpha$ subunit.

\section{Bioelectric Measurements in the Airway}

Electrogenic nasal epithelial sodium transport was absent in patients with systemic pseudohypoaldosteronism (Fig. 1). The basal transepithelial potential difference was only about 35 percent of the normal value, and the potential difference was not reduced by perfusing the lumen with amiloride, a sodiumchannel inhibitor (mean $[ \pm S E]$ change, $-0.9 \pm 0.4$ $\mathrm{mV}$ ), or with sodium-free Ringer's solution (mean $[ \pm \mathrm{SE}]$ change in three patients, $+2.7 \pm 1.2 \mathrm{mV}) .^{22}$ The bronchial potential difference measured in one patient (Patient 1 ) was much lower $(-2 \mathrm{mV})$ than that in normal subjects (approximately $-20 \mathrm{mV}$ ) and was not reduced by amiloride. ${ }^{27}$

\section{Volume and Composition of Nasal Surface Liquid}

The volume of nasal surface liquid obtained from the patients with systemic pseudohypoaldosteronism was more than twice that obtained from normal subjects (Fig. 2). The concentration of sodium in the surface liquid from patients with systemic pseudohypoaldosteronism was higher and that of potassium was lower than in the samples from normal subjects or patients with renal pseudohypoaldosteronism (Fig. 2). The surface liquid was approximately isotonic (about $305 \mathrm{mmol}$ per liter) with plasma. 


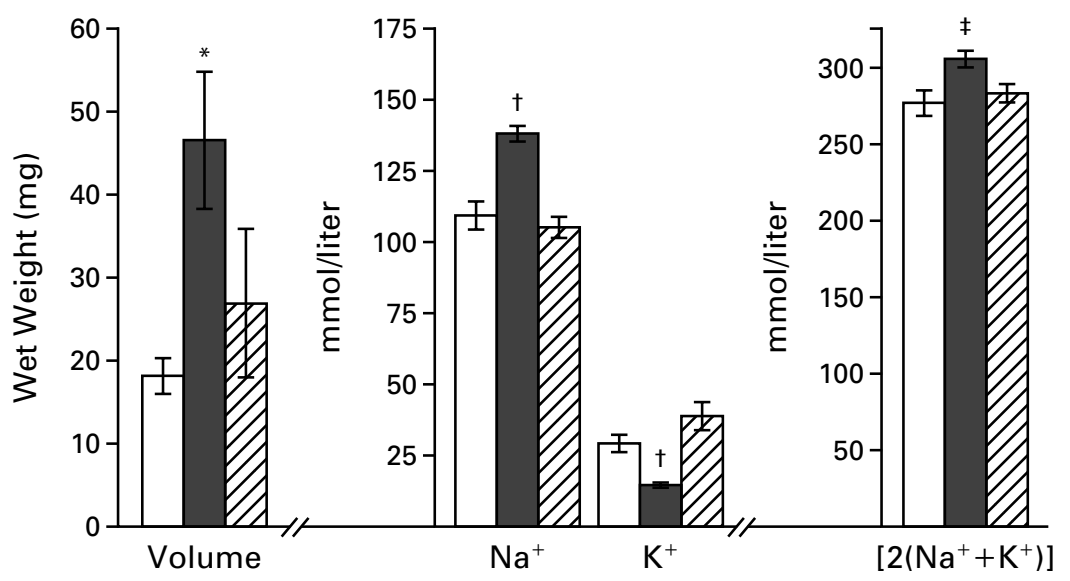

Figure 2. Mean $( \pm \mathrm{SE})$ Volume for Weight, lonic Composition, and Estimated Osmolarity $\left[2\left(\left[\mathrm{NA}^{+}\right]+\left[\mathrm{K}^{+}\right]\right)\right]$ of Nasal Surface Liquid Recovered from Eight Normal Subjects (Open Bars), Eight Patients with Systemic Pseudohypoaldosteronism (Solid Bars), and Three Patients with Renal Pseudohypoaldosteronism (Hatched Bars).

The asterisk indicates $\mathrm{P}=0.009$ for the comparison with normal subjects; the daggers indicate $\mathrm{P}<0.001$ and the double dagger indicates $\mathrm{P}=0.04$ for the comparisons with normal subjects and patients with renal pseudohypoaldosteronism.

Children with systemic pseudohypoaldosteronism had a chronic nasal drip of clear liquid that caused irritation of the philtrum area (Fig. 3A).

\section{Bronchoscopy}

The three patients who underwent diagnostic bronchoscopy (Patients 1, 3, and 4) had a large volume of bronchial surface liquid (Fig. 3B). The protein concentration of the liquid was 24 and $40 \mathrm{mg}$ per deciliter $(<\mathrm{l}$ percent of the serum protein concentration) in the two patients in whom it was measured (Patients 3 and 4 , respectively), and the mean osmolality was $298 \mathrm{mOsm}$ per kilogram. The concentration of sodium in the liquid was high ( $141 \pm 10 \mathrm{mmol}$ per liter) and that of potassium was low $(7.9 \pm 3.5 \mathrm{mmol}$ per liter) in comparison with that in normal bronchial surface liquid. ${ }^{23}$

\section{Microbiologic Examination}

There were inflammatory cells and bacteria in the bronchial-lavage fluid from the three patients who underwent bronchoscopy. The proportion of neutrophils ranged from 10 to 79 percent of the recovered cells. One patient (Patient 1 ) had a large amount of cloudy liquid in the proximal airways, from which Moraxella catarrbalis and Haemophilus influenzae were cultured (100,000 and 40,000 colony-forming units per milliliter, respectively). In two patients (Patients 3 and 4) in whom the liquid was clear, Streptococcus pneumoniae was cultured (50,000 and 100,000 colony-forming units per milliliter, respectively). The five older patients ( 6 to 22 years of age) produced small sputum samples that contained only normal flora.

\section{Pulmonary-Function Tests}

The results of spirometry were normal in seven patients who were tested when they were not acutely ill. Of the four children tested, three (Patients 3, 4, and 6) had mild air trapping (increased functional residual capacity or residual volume), whereas the three adults did not. Methacholine-challenge tests were positive in four of the five patients tested (Patients 3, 4, 6, and 9). However, only two of seven patients treated with bronchodilators had improvement on spirometric measurements or clinical benefit, and only one had a clinical response to treatment with inhaled glucocorticoids.

\section{Radiographic Studies}

Patients six years of age or less had hyperinflation, apparent bronchial thickening, and intermittent segmental atelectasis, but no evidence of bronchiectasis or lobar consolidation. Chest radiographs in the older patients were normal. Sinus radiographs were normal in seven of eight patients.

\section{Mucociliary Clearance}

There was rapid transport of radiotracer in the three patients with systemic pseudohypoaldosteronism in whom we tested mucociliary clearance (Fig. 4 ). The mean clearance rate in the 3 patients was more rapid than in the 12 normal subjects $(2.0 \pm 0.7$ vs. $0.5 \pm 0.3$ percent per minute for the initial $20 \mathrm{~min}$ utes, $\mathrm{P}=0.009) .25$

\section{DISCUSSION}

The patients with systemic pseudohypoaldosteronism had the typical clinical features of the disor- 


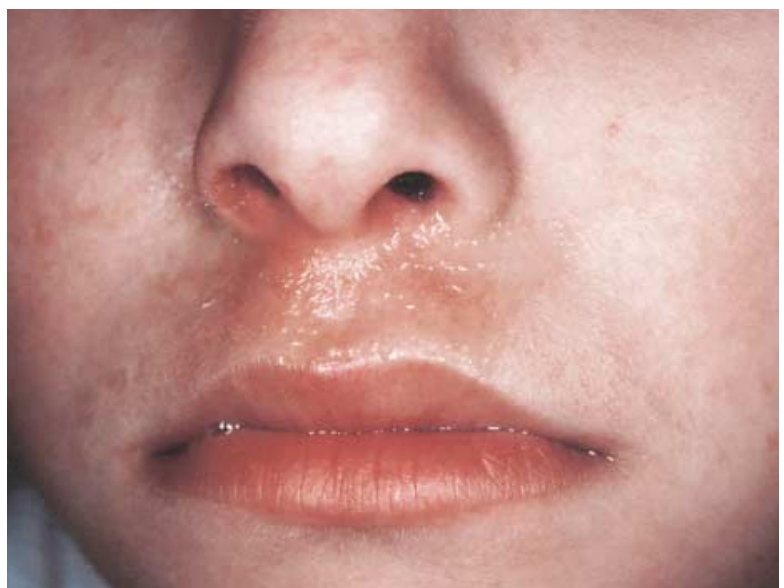

A
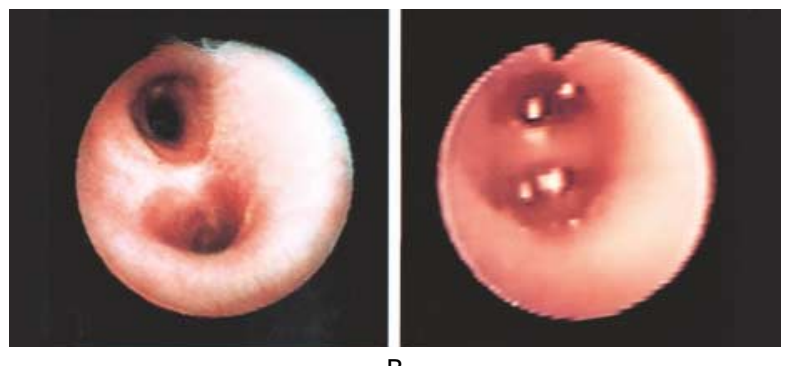

B

Figure 3. Excess Airway Liquid in Patient 3, a Six-Year-Old Boy with Systemic Pseudohypoaldosteronism.

Panel A shows chronic nasal drainage of clear liquid in the absence of viral or allergic rhinitis and the irritation of the philtrum area resulting from the nasal drainage. Panel B shows transbronchoscopic views of the bronchial surfaces in a normal subject, six years of age, who underwent bronchoscopy because of a possible foreign body (left) and the patient with systemic pseudohypoaldosteronism (right).

der, with severe neonatal salt wasting, hyponatremia, hyperkalemia, metabolic acidosis, high serum aldosterone concentrations, and recurrent respiratory illness in the first years of life. ${ }^{1-3,5}$ These patients required high doses of salt replacement into adulthood. These clinical features contrasted with those of the patients with renal pseudohypoaldosteronism, in whom the disease was limited to the kidney and who did not require dietary salt supplementation after the age of five years.

We identified frame-shift, deletion, or stop mutations in the genes for the subunits of the epithelial sodium channel on both alleles in six of the nine patients with systemic pseudohypoaldosteronism (Table 1). These mutations cause systemic pseudohypoaldosteronism, probably by eliminating sodium-channel function. $2,3,28$ The three patients with no identified mutations may have intronic or promoter mutations or mutations in other proteins responsible for the assembly or function of sodium channels.

The patients with systemic pseudohypoaldosteronism had a total absence of electrogenic sodium transport in the upper and lower airways (Fig. 1). The chief physiologic consequence of defective sodium transport was an increase in the volume of airway surface liquid. The presence of excessive liquid on airway surfaces was associated with a distinct respiratory syndrome. Children had persistent rhinorrhea of clear liquid, with chronically chapped upper lips. In the first years of life, these children also had recurrent respiratory illnesses characterized by congestion, tachypnea, wheezing, and frequently fever. Although aspects of these illnesses were suggestive of asthma, only two of the patients had high serum IgE concentrations (Patients 7 and 9), and they did not benefit from therapy with aerosolized $\beta$-adrenergic agonists or glucocorticoids.

We speculate that the pulmonary syndrome in patients with systemic pseudohypoaldosteronism is caused by an excessive volume of surface liquid that narrows airway lumens and dilutes surface-active materials that stabilize small airways, ${ }^{29,30}$ predisposing the patients to wheezing and airway infections early in life. As in viral bronchiolitis, airway narrowing due to intraluminal liquid may be more prominent in infancy and early childhood when the airway diameter is small. This speculation is compatible with the positive results of methacholine challenge in four of the five patients tested; such results can be due to a decreased airway caliber in patients who do not have atopy. ${ }^{31,32}$

The failure to absorb liquid as it moves up the converging surfaces of the airways predicts that sufficient liquid will accumulate on proximal airways to produce airflow obstruction - that is, "intrapulmonary drowning." 7 To compensate for the failure to absorb liquid from airway surfaces in patients with systemic pseudohypoaldosteronism, the rate of mucociliary clearance increases to remove some of the excess volume from airway surfaces. The mechanism of the increased rate of mucociliary clearance in these patients is unclear. The efficiency of mucociliary clearance is thought to be dependent on contact of ciliary tips with the inner surface of a layer of mucus. Our data from patients with systemic pseudohypoaldosteronism suggest that an expansion of the volume of airway surface liquid does not "float" mucus off the tips of cilia and slow mucociliary clearance. It is more likely that the excess volume is added to the mucous layer, improving its biorheologic properties and clearance rates. 7,33

The functional defects in the airway epithelium of patients with systemic pseudohypoaldosteronism provide insights into the relations among epithelial sodium transport, the volume and composition of air- 


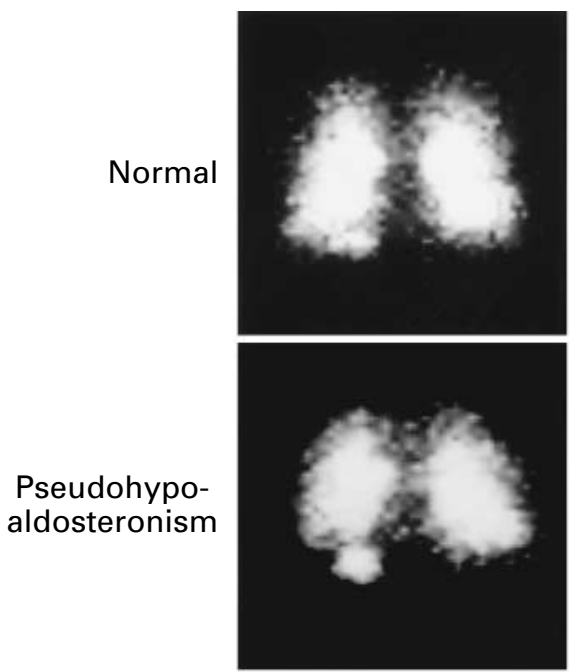

0
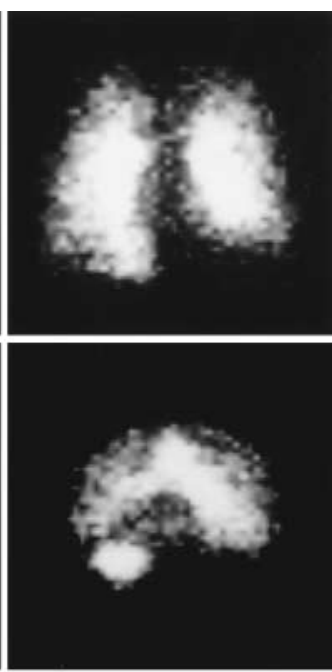

10
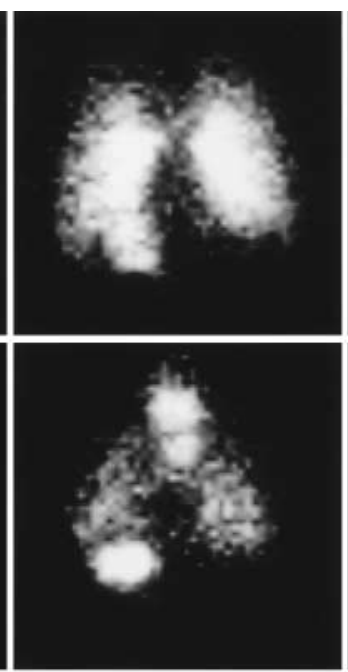

20
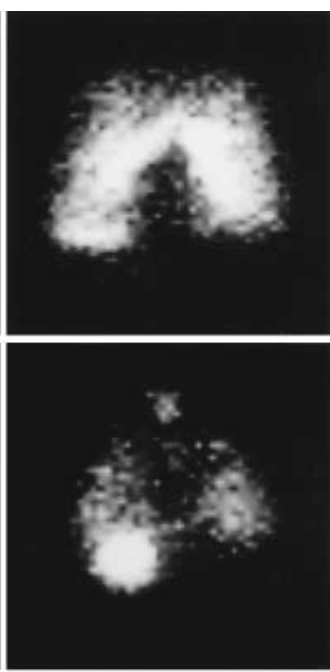

30

Minutes

Figure 4. Posterior Gamma-Camera Radionuclide Images of Whole-Lung Clearance in a Normal Subject and a Patient with Systemic Pseudohypoaldosteronism Immediately after Inhalation of Technetium-99m-Labeled Iron Oxide Particles and 10, 20, and 30 Minutes Later.

The distribution of tracer is relatively uniform in both base-line images, but there is rapid clearance of particles into the proximal airways of the patient with pseudohypoaldosteronism (10 minutes). There is a sequential increase in the accumulation of tracer in the stomach (beneath the left lung).

way surface liquid, and the pathogenesis of airway disease, including cystic fibrosis. Some have suggested that the function of sodium transport in the airway epithelium is to generate hypotonic (i.e., low sodium and low chloride) airway surface liquid that promotes the antimicrobial activities of salt-sensitive defensins. ${ }^{10,11}$ According to this hypothesis, chronic bacterial airway infections in patients with cystic fibrosis reflect the inability of the airway epithelium to lower the concentration of sodium and chloride in airway surface liquid, thereby inactivating defensins and promoting infection. Others have suggested that sodium transport normally regulates the volume of an isotonic airway surface liquid, and that this regulation is important for mucus clearance. ${ }^{23,27,33}$ According to this hypothesis, sodium and volume absorption is increased in cystic fibrosis, mucus transport is abolished, and chronic infection follows. ${ }^{33}$ The data from the patients with systemic pseudohypoaldosteronism argue for the latter hypothesis: sodium transport is linked to regulation of the volume of airway surface liquid, not to its tonicity, and chronic bacterial airway infection is not associated with isotonic airway surface liquid if mucus clearance is preserved.

In summary, studies of patients with systemic pseudohypoaldosteronism demonstrate the linkage between sodium transport and the volume of airway surface liquid, rather than its tonicity, in lung physiology. The pulmonary disease in young children with systemic pseudohypoaldosteronism represents a novel form of airway disease associated with the excess volume of airway surface liquid resulting from defective sodium-dependent liquid absorption. An increase in the rate of clearance of liquid from airway surfaces by mucociliary transport appears to compensate, in part, for the failure to absorb liquid transepithelially.

Supported by grants from the Cystic Fibrosis Foundation (CFF RDP R026), the National Heart, Lung, and Blood Institute (P01 HL34322), and the National Institutes of Health (RR00046).

We are indebted to Michael Wilshanski, M.D., Joe Robinson, M.S., Carla Foy, B.S., Kirby Zeman, Ph.D., John Gatzy, Ph.D., and Robert E. Wood, M.D., Ph.D., for assisting in some of the studies; to William Brandenburger, M.D., Francine R. Kaufman, M.D., Michael Schechter, M.D., and Beth Steindel, M.D., for assisting in the care of the patients; to George Chrousos, M.D., Larry Kirschner, M.D., and Maria New, M.D., for referral of patients; and to Lisa Brown and Beth Godwin for editorial assistance.

\section{REFERENCES}

1. Hanukoglu A. Type I pseudohypoaldosteronism includes two clinically and genetically distinct entities with either renal or multiple target organ defects. J Clin Endocrinol Metab 1991;73:936-44.

2. Chang SS, Grunder S, Hanukoglu A, et al. Mutations in subunits of the epithelial sodium channel cause salt wasting with hyperkalaemic acidosis, pseudohypoaldosteronism type I. Nat Genet 1996;12:248-53.

3. Strautnieks SS, Thompson RJ, Gardiner RM, Chung E. A novel splicesite mutation in the gamma subunit of the epithelial sodium channel gene in three pseudohypoaldosteronism type 1 families. Nat Genet 1996;13: 248-50. 
4. Geller DS, Rodriquez-Soriano J, Vallo Boado A, et al. Mutations in the mineralocorticoid receptor gene cause autosomal dominant pseudohypoaldosteronism type I. Nat Genet 1998;19:279-81.

5. Hanukoglu A, Bistritzer T, Rakover Y, Mandelberg A. Pseudohypoaldosteronism with increased sweat and saliva electrolyte values and frequent lower respiratory tract infections mimicking cystic fibrosis. J Pediatr 1994; 125:752-5.

6. Marthinsen L, Kornfalt R, Aili M, Andersson D, Westgren U, Schaede C. Recurrent Pseudomonas bronchopneumonia and other symptoms as in cystic fibrosis in a child with type I pseudohypoaldosteronism. Acta Paediatr 1998;87:472-4

7. Kilburn $\mathrm{KH}$. A hypothesis for pulmonary clearance and its implications. Am Rev Respir Dis 1968;98:449-63.

8. Boucher RC. Human airway ion transport. Am J Respir Crit Care Med 1994;150:271-81.

9. Wanner A, Salathe M, O'Riordan TG. Mucociliary clearance in the airways. Am J Respir Crit Care Med 1996;154:1868-902.

10. Quinton PM. Viscosity versus composition in airway pathology. Am J Respir Crit Care Med 1994;149:6-7.

11. Smith JJ, Travis SM, Greenberg EP, Welsh MJ. Cystic fibrosis airway epithelia fail to kill bacteria because of abnormal airway surface fluid. Cell 1996;85:229-36. [Erratum, Cell 1996;87:355a.]

12. Wine JJ. The genesis of cystic fibrosis lung disease. J Clin Invest 1999; 103:309-12.

13. Working Group of the European Society of Pediatric Gastroenterology and Nutrition. A standardized protocol for the methodology of esophagea $\mathrm{pH}$ monitoring and interpretation of the data for the diagnosis of gastro esophageal reflux. J Pediatr Gastroenterol Nutr 1992;14:467-71.

14. Oberfield SE, Levine LS, Carey RM, Bejar R, New MI. Pseudohypoaldosteronism: multiple target organ unresponsiveness to mineralocorticoid hormones. J Clin Endocrinol Metab 1979;48:228-34

15. Skin tests used in type I allergy testing position paper: Sub-Committee on Skin Tests of the European Academy of Allergology and Clinical Immunology. Allergy 1989;44:Suppl 10:1-59.

16. Hargreave FE, Ryan G, Thomson NC, et al. Bronchial responsiveness to histamine or methacholine in asthma: measurement and clinical significance. J Allergy Clin Immunol 1981;68:347-55.

17. Avital A, Bar-Yishay E, Springer C, Godfrey S. Bronchial provocation tests in young children using tracheal auscultation. J Pediatr 1988;112:591-

18. Lodrup-Carlsen $\mathrm{KC}$, Carlsen $\mathrm{KH}$. Lung function in awake healthy infants: the first five days of life. Eur Respir J 1993;6:1496-500.
19. Gerhardt T, Hehre D, Bancalari E, Watson H. A simple method for measuring functional residual capacity by $\mathrm{N}_{2}$ washout in small animals and newborn infants. Pediatr Res 1985;19:1165-9.

20. Highsmith WE, Burch LH, Zhou A, et al. A novel mutation in the cystic fibrosis gene in patients with pulmonary disease but normal sweat chloride concentrations. N Engl J Med 1994;331:974-80.

21. Knowles MR, Paradiso AM, Boucher RC. In vivo nasal potential difference: techniques and protocols for assessing efficacy of gene transfer in cystic fibrosis. Hum Gene Ther 1995;6:445-55

22. Knowles M, Gatzy J, Boucher R. Relative ion permeability of normal and cystic fibrosis nasal epithelium. J Clin Invest 1983;71:1410-7.

23. Knowles MR, Robinson JM, Wood RE, et al. Ion composition of air way surface liquid of patients with cystic fibrosis as compared with normal and disease-control subjects. J Clin Invest 1997;100:2588-95. [Erratum, J Clin Invest 1998;101:285.]

24. Gilligan PH. Microbiology of airway disease in patients with cystic fibrosis. Clin Microbiol Rev 1991;4:35-51.

25. Olivier KN, Bennett WD, Hohneker KW, et al. Acute safety and effects on mucociliary clearance of aerosolized uridine 5 '-triphosphate $+/$ amiloride in normal human adults. Am J Respir Crit Care Med 1996;154 217-23.

26. Zar JH. Biostatistical analysis. 3rd ed. Upper Saddle River, N.J.: Prentice-Hall, 1996

27. Boucher RC. Human airway ion transport. Am J Respir Crit Care Med 1994; 150:581-93

28. Li X-J, Xu R-H, Guggino WB, Snyder SH. Alternatively spliced forms of the alpha subunit of the epithelial sodium channel: distinct sites for amil oride binding and channel pore. Mol Pharmacol 1995;47:1133-40.

29. Clark JC, Weaver TE, Iwamoto HS, et al. Decreased lung compliance and air trapping in heterozygous SP-B-deficient mice. Am J Respir Cell Mol Biol 1997;16:46-52.

30. Yager D, Butler JP, Bastacky J, Israel E, Smith G, Drazen JM. Amplification of airway constriction due to liquid filling of airway interstices. J Appl Physiol 1989;66:2873-84

31. Mitchell I, Corey M, Woenne R, Krastins IRB, Levinson H. Bronchia hyperreactivity in cystic fibrosis and asthma. J Pediatr 1978;93:744-8.

32. Sanchez I, Powell RE, Pasterkamp H. Wheezing and airflow obstruc tion during methacholine challenge in children with cystic fibrosis and in normal children. Am Rev Respir Dis 1993;147:705-9.

33. Matsui H, Grubb BR, Tarran R, et al. Evidence for periciliary liquid layer depletion, not abnormal ion composition, in the pathogenesis of cyst ic fibrosis airways disease. Cell 1998;95:1005-15. 